\title{
Crescimento da agropecuária cearense: comparação entre as produtividades parciais e total
}

\author{
Monaliza de Oliveira Ferreira* \\ Lúcia Maria Ramos** \\ Antônio Lisboa Teles da Rosa ***
}

Resumo: A agricultura tem se mostrado um importante setor na contribuição ao crescimento econômico, tanto em países desenvolvidos como em países em desenvolvimento. Sendo assim, o objetivo deste artigo foi analisar o crescimento da agropecuária cearense a partir da observação e comparação das produtividades parciais e total, no período de 1975-1995, considerando as sete mesorregiões do estado. Para isso, utilizou-se o índice de Törnqvist-Theil, que mede a produtividade. Os dados utilizados foram secundários do tipo cross-section, de acordo com os Censos Agropecuários do Ceará (1975, 1980, 1985 e 1995) - IBGE. Conclui-se que as pequenas variações na produtividade da agropecuária cearense praticamente não afetaram as mudanças estruturais ocorridas, o que indica que as políticas públicas implementadas no período não foram suficientes, haja vista os pequenos ganhos de produtividade alcançados. Dessa forma, espera-se que sejam implementadas políticas públicas também nas áreas cujas condições edafo-climáticas são menos favoráveis, dificultando a vida do trabalhador rural e levando, muitas vezes, à migração rural-urbana.

Palavras-chave: crescimento, produtividades parciais e total.

Classificação JEL: 013

* Mestre em Economia Rural -UFC/Doutoranda em Economia pelo PIMES/UFPE. monaliza_ferreira@yahoo.com.br;

** Professora Livre Docente do Depto de Economia Agrícola da UFC. 1ramos@ufc.br;

***Professor Adjunto da UFC/CAEN. lisboa@ipece.ce.gov.br. 
Abstract: Agriculture shows itself as an important sector for contributing to the economic growth, as in developed countries as in developing countries. So, the objective of this article was to analyze the growth of the agriculture of Ceara based on the observation and comparison of the partial and total farming productivities, in the 1975-1995 period, considering the seven Meso-Regions of the State. For that purpose it was employed the index of Törnqvist-Theil, which measures the achieved farming productivities. The used data were secondary of the type cross-section, in agreement with the Agricultural Censures of Ceará, for the years of 1975, 1980, 1985 and 1995, published by IBGE. The conclusion is that the small changes in the farming productivity of Ceará practically have no affected on the structural changes occurred, what indicates that the public policies implemented in the period weren't sufficient, as indicates the small farming productivity gain reached. Considered this, it is expected the implementation of public policies also in the areas whose edafoclimatic conditions are less favorable, what difficults the life of the rural worker and often leads to rural-urban migration.

Key words: growth, partial and total productivities.

\section{JEL Classification: 013}

\section{Introdução}

O discurso internacional sobre desenvolvimento econômico situa a agricultura como setor estratégico para aferição de taxas maiores de crescimento econômico, acompanhadas de um melhor padrão de vida da população. Ressalte-se que foi a partir dos incentivos à agricultura que os avanços tecnológicos viabilizaram a industrialização nos países centrais.

As incertezas econômicas e sociais, aliadas ao desgaste dos recursos naturais e crescimento da população, especialmente nos países pobres, levam as nações periféricas a também optar pela transformação da agricultura, investindo em pesquisa de alta qualidade, dentro da qual a Biotecnologia terá um papel cada vez maior, ao lado de políticas de investimento e de mudanças estruturais (VILELA, 1999). Tem-se verificado, inclusive, que a agricultura desempenhou e continua desempenhando papel decisivo no combate à pobreza em boa parte dos países. 
Entretanto, a modernização da agricultura brasileira, intensificada em meados da década de 1960, levou a uma subordinação crescente da agricultura à indústria, acarretando transformações sociais, econômicas e ambientais no campo, que levaram, dentre outras coisas, à concentração da estrutura fundiária, como relata REIS JÚNIOR (1996).

A modernização da agropecuária nordestina e cearense tomou impulso na década de 1970, com a construção de grandes perímetros irrigados públicos - que associava à irrigação pública projetos de assentamento, produção de alimentos, colonização e incentivo à produção familiar. Foram construídos 27 desses perímetros irrigados, dentre os quais, nove no Ceará, incluindo as bacias hidrográficas do Jaguaribe, Salgado, Acaraú e Curu.

Apesar dos índices de crescimento atribuídos à Região Nordestina pelas instituições competentes nos últimos anos, ela apresenta heterogeneidade em sua estrutura agrícola, onde coexistem subemprego, instabilidade no emprego e baixa renda, além de grandes disparidades no nível tecnológico entre pequenos e grandes produtores rurais.

Similarmente ao setor agropecuário da região Nordeste, no Estado do Ceará, enfrentam-se sérios problemas. A agricultura, em especial, caracteriza-se pela presença de grande número de pequenos produtores agropecuários, grande concentração de terra, baixa produtividade e irregularidades das chuvas.

Embora haja grande diversidade de produtos cultivados no estado, o baixo nível tecnológico adotado nos cultivos explica, em boa parte, o atraso, a grande vulnerabilidade e a baixa produtividade da economia agrícola cearense. Relativamente aos pequenos produtores, parte considerável ainda se dedica à agricultura de subsistência, ficando, portanto, mais predispostos e bastante influenciados pelos efeitos dos fatores citados. Ademais, defrontam-se com outros problemas que influenciam seus resultados, tais como a escassez de recursos financeiros próprios ou financiados e a comercialização, especialmente, por sua baixa escala de produção e pouco ou nenhum poder de barganha (KHAN et al., 1999).

Apesar dos problemas mencionados, a agricultura é um setor particularmente importante para a economia cearense e tem dado, historicamente, uma inquestionável contribuição ao desenvolvimento do estado, participando na geração de emprego, renda e divisas. Nos últimos 
anos, o Ceará vem demonstrando crescimento sucessivo do PIB, com taxas superiores às do Nordeste e Brasil, além de índices crescentes em suas exportações (ROSA, ALVES, 2001).

Não resta dúvida de que o estado cresceu no período próximo passado, mas os dados indicam que este crescimento não ocorreu da mesma forma nos diversos setores e/ou regiões e a distribuição desse crescimento é que viabiliza o desenvolvimento econômico.

Destarte, o grande questionamento que se faz é: em que medida as transformações ocorridas com a economia agropecuária cearense no período de 1975 a 1995 afetaram o produto?

\section{Metodologia}

\subsection{Referencial Teórico}

O que determina o crescimento do produto de um país ou região? Em toda a História Econômica, muitos economistas tentaram responder a essa questão. Para os fisiocratas, a terra era o principal elemento da produção; Adam Smith elegeu o capital como elemento fundamental; Karl Marx enfatizou o papel do trabalho; Joseph Schumpeter mostrou a importância da inovação tecnológica. Hoje, estudos mais recentes apontam para um conjunto de elementos onde se arrolam a organização dos produtores, o mercado, a tecnologia, além da terra, capital e trabalho. Todos esses elementos, conjuntamente, determinam o crescimento do produto do setor rural que impulsionará o crescimento do produto do setor urbano.

Pode-se falar de competitividade entre países, setores ou empresas. Mas os novos padrões de competitividade exigidos pelo mercado globalizado sempre passam pela necessidade de aumentos de produtividade. Entre os estudos mais recentes que tratam do crescimento da agricultura e a relação com a produtividade para o Brasil, pode-se citar: GASQUES, CONCEIÇÃO (1997, 2000, 2001); DIAS, AMARAL (2001), STADUTO, FREITAS (2001); VICENTE, ANEFALOS, CASER (2001); CUNHA (2001); GUERREIRO (1996); LEMOS, FERNANDES, BRANDT (1984); CARTAXO (1989), entre outros.

Partindo do conceito de que a produtividade constitui-se na relação 
entre o produto gerado e todos os insumos utilizados no processo produtivo, faz-se mister examinar a contribuição desses fatores em conjunto.

O conceito de produtividade está implicitamente ligado a uma função de produção do tipo:

$$
Y=f\left(b_{1}, b_{2}, b_{3}, \ldots, b_{n}, t\right)
$$

Onde: $\mathrm{Y}=$ produto;

$$
\begin{aligned}
& \text { bi }=\text { quantidade de insumos; } \\
& i=1,2,3, \ldots, n ; \\
& t=\text { tempo. }
\end{aligned}
$$

A expressão (1) relaciona a quantidade de produto aos insumos necessários para sua obtenção, dados certa tecnologia e um determinado período. A partir dessa função de produção, observa-se a produtividade total dos fatores, conforme a relação entre produto e insumos:

$$
P T F=\frac{f\left(b_{1}, b_{2}, b_{3}, \ldots, b_{n}, t\right)}{\sum w_{i} b_{i}}
$$

Onde: bi = quantidade de insumo;

wi = peso do insumo;

$\mathrm{i}=1,2,3, \ldots, \mathrm{n}$.

Outra forma de mensurar a produtividade total dos fatores despreza o conhecimento de função de produção, utilizando-se o Sistema de Contas Nacionais, partindo da relação entre produto e renda, conforme explicitado em GASQUES, CONCEIÇÃO (op.cit.) e em CARTAXO (op.cit.):

$\sum_{a=1}^{n} P_{a} Y_{a}=\sum_{b=1}^{m} P_{b} X_{b}$

Em que, Pa é o preço do produto a, Pb é o preço do insumo b, Ya é a quantidade de produto a e Xb é a quantidade de insumo b.

$$
\begin{aligned}
& \sum_{a=1}^{n}\left(Y_{a} \frac{d P_{a}}{d_{t}}+P_{a} \frac{d Y_{a}}{d_{t}}\right)=\sum_{b=1}^{m}\left(X_{b} \frac{d P_{b}}{d_{t}}+P_{b} \frac{d X_{b}}{d_{t}}\right) \\
& \sum_{a} \frac{Y_{a} P_{a}}{\sum Y_{a} P_{a}}\left(\frac{d P_{a} / d_{t}}{P_{a}}+\frac{d Y_{a} / d_{t}}{Y_{a}}\right)=\sum_{b} \frac{X_{b} P_{b}}{\sum X_{b} P_{b}}\left(\frac{d P_{b} / d_{t}}{P_{b}}+\frac{d X_{b} / d_{t}}{X_{b}}\right)
\end{aligned}
$$


Em suma, tem-se que:

$$
\sum_{a} S_{a} \frac{\Phi_{a}}{P_{a}}+\sum_{a} S_{a} \frac{\Psi_{a}}{Y_{a}}=\sum_{b} C_{b} \frac{\Theta_{b}}{P_{b}}+\sum_{b} C_{b} \frac{\Omega}{X_{b}}
$$

Onde, $\mathrm{Sa}$ e $\mathrm{Cb}$ correspondem às participações relativas do produto a no produto total e do insumo b no insumo total.

Generalizando a expressão (6), tem-se:

$$
\frac{\Phi}{P}+\frac{\Psi}{Y}=\frac{\Theta}{P}+\frac{\Omega}{X}
$$

Em que, $\frac{\Psi}{Y}$ e $\frac{\Omega}{X}$ são os índices de quantidade de Divisia ${ }^{1}$, enquanto $\frac{\Phi}{P}$ e $\frac{\Theta}{P}$ são os índices de preço de Divisia ${ }^{2}$. A determinação da produtividade total dos fatores, a partir dos índices de Divisia, pode se dar tanto com relação aos índices de preço como de quantidade.

Optou-se por trabalhar com quantidades, conforme demonstrado na expressão (8):

$$
P T F=\left(\frac{\Psi}{Y}-\frac{\Omega}{X}\right)=\left(\sum S_{a} \frac{\Psi_{a}}{Y_{a}}-\sum C_{b} \frac{\Omega_{b}}{X_{b}}\right)
$$

\subsection{Métodos de Análise}

Os métodos selecionados para este estudo foram ultimamente utilizados por GASQUES, CONCEIÇÃO (op.cit.), que realizaram estudos sobre a produtividade total dos fatores, contemplando todos os estados brasileiros, além de uma série de outros autores anteriormente referidos.

a) Indicador de Produtividade Total dos Fatores (PTF)

Adotar-se-á o índice de Törnqvist-Theil, significando que será utilizada a medida de produtividade a partir do Sistema de Contas Na-

${ }^{1}$ Expressa a relação entre o total da produção e as participações de cada produto no total da produção e, da mesma forma, a relação entre o total de fatores utilizados no processo de produção e as participações de cada fator no total de fatores.

${ }^{2}$ Apresenta um conceito similar ao índice de quantidade de Divisia. A diferença consiste em se trabalhar com valores monetários em vez de quantidades. 
cionais, em vez do método a partir da função de produção, conforme explicitado anteriormente. Esse índice é derivado da expressão (3) e é formado a partir das equações do índice do produto e índice dos fatores de produção .

$$
P T F_{t} / P_{T F}=\left(\frac{\left(\frac{1}{2}\right) \sum_{a=1}^{n}\left(S_{a t}+S_{a t-1}\right) \ln \left(\frac{Y_{a t}}{Y_{a t-1}}\right)}{\left(\frac{1}{2}\right) \sum_{b=1}^{m}\left(C_{b t}+C_{b t-1}\right) \ln \left(\frac{X_{b t}}{X_{b t-1}}\right)}\right)
$$

Ao se aplicar logaritmos à expressão (9) chega-se à formulação geral de Törnqvist-Theil, que se apresenta de forma discreta e não contínua, ideal para análise de variáveis econômicas. Esse índice, como visto, é uma aproximação de um outro indicador, o índice de Divisia, CHAMBERS (1998) apud GASQUES, CONCEIÇÃO (op.cit.):

$$
\ln \left(P T F_{t} / P T F_{t-1}\right)=\frac{1}{2} \sum_{a=1}^{n}\left(S_{a t}+S_{a t-1}\right) \ln \left(\frac{Y_{a t}}{Y_{a t-1}}\right)-\frac{1}{2} \sum_{b=1}^{m}\left(C_{b t}+C_{b t-1}\right) \ln \left(\frac{X_{b t}}{X_{b_{t-1}}}\right)
$$

O lado esquerdo da expressão (10) é o logaritmo da razão das quantidades em dois períodos de tempo sucessivos, ponderados pela média móvel da participação de cada produto no valor total da produção. Já o lado direito representa o logaritmo da razão das quantidades de insumos em dois períodos sucessivos, ponderados pela média móvel da participação de cada insumo no custo total.

Ao se trabalhar com índices em períodos muito longos, pode-se admitir a ocorrência de alterações substanciais na estrutura econômica. Isso pode levar a vieses significativos quando se utiliza uma base fixa. Para que tal não aconteça, recomenda-se que as séries sejam montadas

\footnotetext{
${ }^{3}$ No numerador tem-se o índice do produto, em que y se refere à medida do produto, Ya consiste na quantidade do produto a e Sa é a participação do produto a no valor total da produção. Já o denominador refere-se ao índice dos fatores de produção, onde x é a medida dos fatores de produção, Xb é a quantidade do insumo b e Cb refere-se à participação do insumo b no custo total dos insumos. Essas expressões são mais detalhadas em GASQUES, CONCEIÇÃO (1997 e 2000).
} 
em um processo de encadeamento, com o que se terá a atualização periódica da base de cálculo [SILVA, CARMO (1986) apud VICENTE, ANEFALOS, CASER (s/d)].

A relação entre a produtividade total dos fatores no período " $\mathrm{t}$ " $\mathrm{e}$ no período imediatamente anterior " $t-1$ " é obtida através do exponencial da expressão (10). Em seguida, considera-se um ano-base qualquer como igual a 100 e faz-se o encadeamento dos demais anos a partir da fórmula descrita a seguir, para que se possa obter o índice de produtividade total em cada ano considerado.

$$
\begin{aligned}
& Y^{e}{ }_{t}=Y_{t} \cdot Y^{e}{ }_{t-1} \\
& Y^{e}{ }_{t+1}=Y_{t+1} \cdot Y^{e}{ }_{t} \\
& Y^{e}{ }_{t+2}=Y_{t+2} \cdot Y^{e}{ }_{t+1}
\end{aligned}
$$

Esse processo de base móvel, onde o índice é calculado em relação ao ano anterior e não apenas em relação a um único ano-base, foi descrito em HOFFMANN (1980).

b) Taxas de Crescimento

As taxas de crescimento foram calculadas a partir da expressão (12), conforme descritas em STADUTO, FREITAS (op.cit.).

$i=\left(V_{1} / V_{0}\right)^{1 / t}-1$

Onde: $\mathrm{i}=$ taxa de crescimento;

$\mathrm{V} 1$ = ano final;

$\mathrm{V} 0$ = ano inicial;

$\mathrm{t}=$ quantidade de anos entre V0 e V1.

\subsection{Definição das Variáveis e Fonte dos Dados}

Como descrito, a mensuração da produtividade deu-se pela relação entre um índice do produto, a partir das quantidades produzidas 
de cada produto e o uso correspondente dos fatores de produção. É interessante que se incorpore o maior número de produtos e insumos para se ter um resultado mais real. No entanto, considerou-se apenas os produtos mais significativos, os quais se encontram relacionados no Quadro 1, em virtude dos demais se apresentarem com pouca expressividade na produção agropecuária do estado. Esse procedimento visou a conceder maior visão aos principais produtos.

Quadro 1 - Produtos Utilizados

\begin{tabular}{|ll}
\hline Lavouras & Alface \\
Algodão arbóreo & Pimentão \\
Cana-de-açúcar & Extração vegetal \\
Feijão em grão & Lenha \\
Mandioca & Madeira \\
Milho em grão & Pecuária \\
Tomate & Bovinos \\
Algodão arbóreo & Suínos \\
Banana & Ovinos \\
Castanha de caju & Caprinos \\
Coco-da-baía & Aves \\
Laranja & Leite de vaca \\
Manga & Ovos de galinha \\
\hline
\end{tabular}

Fonte: Censo Agropecuário do Ceará - IBGE.

Em geral, trabalha-se com preços e quantidades para se obter a produtividade dos fatores. Entretanto, o ganho em abrangência pode ser suplantado pela inexistência de fontes de preços dos fatores de produção. Isso porque a Fundação Getúlio Vargas (FGV), reconhecidamente geradora de vasto banco de dados de preços para todos os estados, não os produz para um estudo desagregado como este, que estuda mesorregiões. 
A Fundação Instituto Brasileiro de Geografia e Estatística (IBGE), por sua vez, não trabalha com valores para todos os produtos e dificilmente os tem com relação aos custos dos fatores, mesmo nos Censos Agropecuários, uma das mais completas publicações do gênero. Além do mais, o índice geralmente utilizado para atualizar os valores é o Índice Geral de Preço - Disponibilidade Interna (IGP-DI) -, que considera em sua construção produtos da indústria e de serviços, tornando-se inadequado para o trabalho com dados da agropecuária.

Com isso, certamente incorrer-se-ia em erros consideráveis nas medidas de produtividade obtidas. Assim sendo, optou-se por trabalhar com quantidades, pois, mesmo limitando as possibilidades de análise, reduziuse a probabilidade de se estimar falsos índices, mascarando a realidade.

Entretanto, deve-se salientar que, quando se necessita comparar produtos, há que se considerar os valores monetários em vez de quantidades produzidas, haja vista que não é possível a comparação com unidades de medidas diferentes. Os valores dos produtos são encontrados nos Censos Agropecuários, entretanto essas informações não existem para os fatores de produção: logo, não é possível que se realize uma comparação entre esses fatores.

Dessa forma, as variáveis utilizadas nesse estudo foram quantidades para os produtos e insumos utilizados no setor agropecuário, para a mensuração das produtividades nas mesorregiões cearenses no período de 1975-1995.

As quantidades produzidas de origem vegetal, extrativa vegetal e animal foram obtidas junto ao IBGE, através das publicações da Produção Agrícola Municipal (PAM), Produção Pecuária Municipal (PPM) e Censos Agropecuários do Ceará.

Todos os dados utilizados são secundários, cujas fontes encontramse, principalmente, nos Censos Agropecuários do Ceará para os anos de 1975, 1980, 1985 e 1995/1996. Ressalte-se que no Censo Agropecuário de 1995/1996 houve a mudança do ano civil para o ano agropecuário, o que poderia trazer algumas distorções nos resultados, contudo, conforme informações de técnicos do IBGE, foram feitas projeções para os meses faltosos, podendo-se compará-los com os demais sem quaisquer problemas.

As lavouras foram divididas em temporárias e permanentes. Na produção animal, foram observados os dados dispostos conforme publica- 
dos nos Censos Agropecuários, ou seja, referindo-se às quantidades de abatidos mais vendidos de bovinos, suínos, caprinos, ovinos e aves. Já os produtos de origem animal, como ovos e leite, estão disponíveis nos Censos ou Produção Pecuária Municipal.

A informação referente ao uso da terra consistiu nas quantidades de hectares ocupadas com as lavouras permanentes e temporárias, além das pastagens naturais e plantadas.

Para a mão-de-obra, utilizou-se o total de pessoal ocupado, disponíveis nos Censos Agropecuários.

Os dados referentes aos insumos de capital, como lenha, querosene, carvão vegetal, óleo diesel, gasolina e gás liquefeito de petróleo, fertilizantes e defensivos agrícolas, além de tratores, foram retirados dos Censos Agropecuários.

Ressalte-se que o capital foi representado por uma proxy, a partir do uso dos principais insumos, ou seja, representando apenas parte do capital utilizado na agricultura.

\section{Resultados e discussão}

\subsection{Produtividades Parciais da Terra, Trabalho e Capital}

\subsubsection{Produtividade da Terra}

A modernização da agricultura, como se sabe, pode tomar duas direções principais: o aumento da produtividade do trabalho, principalmente através da inserção de tecnologias mecânicas, como tratores, colheitadeiras, semeadeiras, equipamentos e implementos agrícolas, ainda que se tornem um problema do ponto de vista social, em razão do excesso de mão-de-obra; e aumento da produtividade da terra, através de melhores métodos de produção e adoção de insumos modernos, como sementes e mudas aperfeiçoadas, fertilizantes, defensivos e corretivos agrícolas, máquinas e outros equipamentos.

A produtividade da terra, expressa pela relação entre o índice agregado do produto e o índice do fator terra, evidenciada na Tabela 1, revela que o Ceará percorreu uma trajetória oscilante entre o período de 1975-1995, com alternância de ganhos e perdas de produtividade. 
O ano de 1980 destacou-se pela ocorrência dos menores índices de produtividade da terra no estado e também nas mesorregiões, excetuando-se as mesorregiões Metropolitana de Fortaleza e Jaguaribe. A Mesorregião do Jaguaribe apresentou o maior índice de produtividade ao longo do período. De um lado, a Metropolitana de Fortaleza é uma mesorregião menos afetada pela irregularidade climática; de outro, o Jaguaribe apresenta o maior uso de assistência técnica e práticas de irrigação.

Tabela 1 - Índices de Produtividade da Terra para o Estado do Ceará e Mesorregiões, 1975-1995

\begin{tabular}{l||l|r|r|r|r}
\hline \hline & \multicolumn{1}{|c|}{ MESORREGIÕES } & $\mathbf{1 9 7 5}$ & $\mathbf{1 9 8 0}$ & \multicolumn{1}{c|}{$\mathbf{1 9 8 5}$} & \multicolumn{1}{c}{1995} \\
\hline \hline \multirow{2}{*}{1} & CEARÁ & $\mathbf{1 0 0 , 0 0}$ & $\mathbf{8 7 , 3 8}$ & $\mathbf{1 0 1 , 5 3}$ & $\mathbf{9 9 , 5 9}$ \\
2 & Noroeste Cearense & 100,00 & 70,60 & 105,61 & 98,77 \\
3 & Norte Cearense & 100,00 & 79,62 & 98,15 & 100,07 \\
4 & Metropolitana de Fortaleza & 100,00 & 112,38 & 102,85 & 99,73 \\
5 & Sertões Cearenses & 100,00 & 78,60 & 96,49 & 93,09 \\
6 & Jaguaribe & 100,00 & 116,44 & 102,88 & 95,52 \\
7 & Sentro-Sul Cearense & 100,00 & 80,02 & 97,78 & 97,37 \\
\hline \hline
\end{tabular}

Fonte: Elaboração própria, a partir dos dados da pesquisa.

O decréscimo de produtividade em 1980 pode ser explicado em parte pela ocorrência de seca nesse período, com a conseqüente redução no uso produtivo da terra. De acordo com dados da FUNCEME, somente nas mesorregiões Metropolitana de Fortaleza e Jaguaribe, houve regularidade nas chuvas no referido ano, embora o Sul Cearense também tenha se destacado, apresentando maior regularidade nas chuvas do que as demais mesorregiões.

Contudo, as baixas produtividades verificadas no ano de 1980 podem ser explicadas não só pelas condições climáticas, que eram extremamente difíceis, em virtude da seca que persistia desde 1978 e que iria se repetir em 1983 e 1993, afetando mais uma vez a agropecuária cearense, mas também em razão das condições macroeconômicas desfavoráveis, que se refletiram na retirada da política de preços mínimos e redução do crédito rural subsidiado, naquela que foi considerada a "década perdi- 
da" no cenário mundial; além disso, registram-se os escassos recursos financeiros e a falta de políticas públicas eficazes para o convívio com o fenômeno climático e o desenvolvimento agropecuário local.

Em 1985, houve uma recuperação nas produtividades, especialmente no Noroeste Cearense. Possivelmente, esses ganhos foram ocasionados dos reflexos imediatos de algumas ações governamentais através dos programas criados a partir do Projeto Nordeste em 1982, especialmente o Programa de Apoio ao Pequeno Produtor (PAPP), que objetivava aumentar o crédito rural, assistência técnica, pesquisa adaptada e apoio à comercialização, além do Programa de Irrigação.

\subsubsection{Produtividade do Trabalho}

A análise da produtividade do trabalho, expressa pela relação entre o índice agregado do produto e o índice do fator trabalho, revelou algumas semelhanças em relação à produtividade da terra. Em geral, apresentou tendência oscilatória ao longo do período analisado. Também os menores níveis de produtividade deram-se no ano de 1980, como expresso na Tabela 2, excetuando-se, mais uma vez, as mesorregiões Metropolitana de Fortaleza e Jaguaribe. Para essas duas mesorregiões, entretanto, houve os maiores ganhos de produtividade no referido ano. Na Metropolitana de Fortaleza, houve redução na população em idade ativa, entre 1980 e 1996, o que pode sinalizar maior incidência de êxodo rural. O Jaguaribe, por sua vez, possui a maior população rural em idade ativa do estado.

As perdas de produtividade do trabalho ao longo do período analisado também podem ser justificadas pelo fato de que, como os homens geralmente saem em busca de novos trabalhos no meio urbano, ficam as mulheres e crianças encarregadas do trabalho anteriormente realizado pelos chefes masculinos das famílias, o que necessariamente reduz a produtividade, já que esse tipo de trabalho, muitas vezes, depende mais da força física. A falta de empregos permanentes e a baixa remuneração do trabalho são os principais responsáveis por essa migração rural-urbana.

Convém registrar que a perda de produtividade do trabalho, em alguns casos, pode não estar relacionada à redução do pessoal ocupado. $\mathrm{Na}$ verdade, isso depende muito do tipo de atividade a ser explorada e da tecnologia empregada. 
A produtividade do trabalho pode ser desagregada em dois componentes, quais sejam: a produtividade da terra - expressa pela relação entre o produto total e a quantidade de terra - e a relação terra-homem - expressa pela relação entre a quantidade de terra e o número de pessoal ocupado no campo, indicando o número de hectares operados por uma unidade de trabalho, considerando um certo grau de mecanização em determinado período de tempo, conforme se percebe na Tabela 3.

Tabela 2 - Índice de Produtividade do Trabalho para o Estado do Ceará e Mesorregiões, 1975-1995

\begin{tabular}{l|l||r|r|r||r}
\hline \hline & \multicolumn{1}{|c|}{ MESORREGIÕES } & $\mathbf{1 9 7 5}$ & \multicolumn{1}{c|}{$\mathbf{1 9 8 0}$} & \multicolumn{1}{c|}{$\mathbf{1 9 8 5}$} & \multicolumn{1}{c}{$\mathbf{1 9 9 5}$} \\
\hline \hline & CEARÁ & $\mathbf{1 0 0 , 0 0}$ & $\mathbf{9 7 , 3 8}$ & $\mathbf{9 9 , 8 5}$ & $\mathbf{1 0 0 , 0 2}$ \\
1 & Noroeste Cearense & 100,00 & 77,06 & 103,50 & 100,11 \\
2 & Norte Cearense & 100,00 & 90,17 & 95,11 & 101,12 \\
3 & Metropolitana de Fortaleza & 100,00 & 104,94 & 102,22 & 100,06 \\
4 & Sertões Cearenses & 100,00 & 86,87 & 94,22 & 94,51 \\
5 & Jaguaribe & 100,00 & 148,49 & 104,02 & 95,13 \\
6 & Centro-Sul Cearense & 100,00 & 78,16 & 96,67 & 96,26 \\
7 & Sul Cearense & 100,00 & 107,67 & 101,58 & 100,11 \\
\hline \hline
\end{tabular}

Tabela 3 - Taxas Anuais de Crescimento da Produtividade do Trabalho e seus Componentes para o Estado do Ceará e Mesorregiões, 1975-1995 (\%)

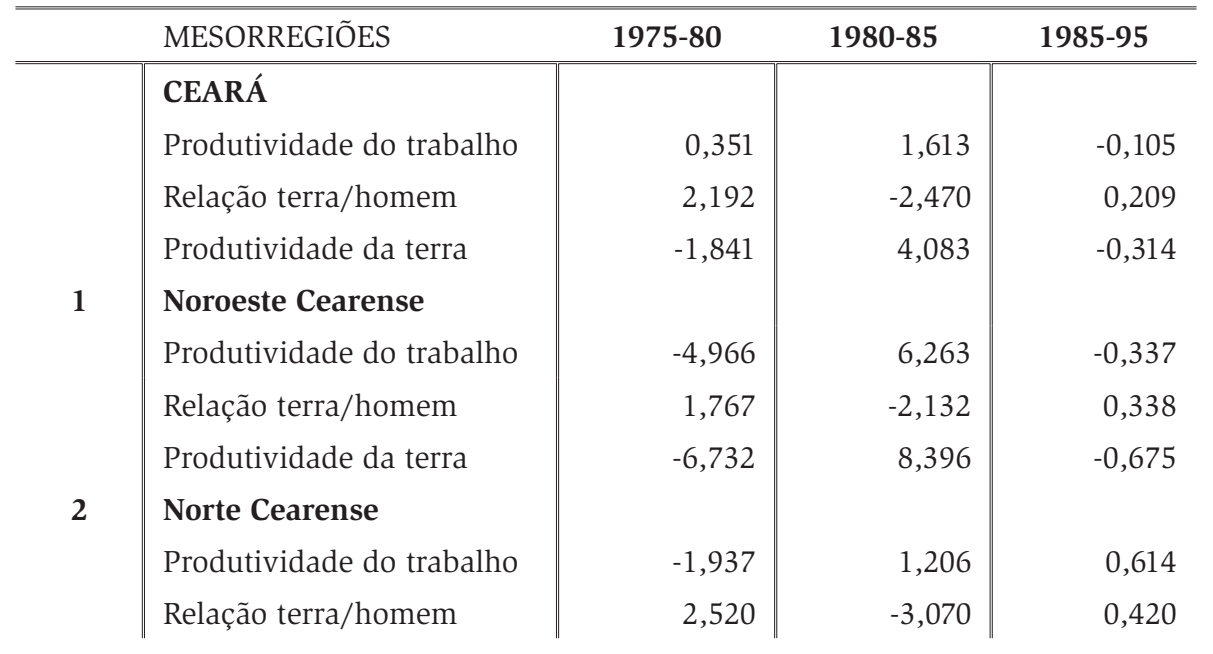


3
Produtividade da terra

Metropolitana de

Fortaleza

Produtividade do trabalho

Relação terra/homem

Produtividade da terra

Sertões Cearenses

Produtividade do trabalho

Relação terra/homem

Produtividade da terra

Jaguaribe

Produtividade do trabalho

Relação terra/homem

Produtividade da terra

Centro-Sul Cearense

Produtividade do trabalho

Relação terra/homem

Produtividade da terra

Sul Cearense

Produtividade do trabalho

Relação terra/homem

Produtividade da terra

\begin{tabular}{r||r||r}
$-4,457$ & \\
& & \\
1,011 & & \\
$-1,361$ & $-0,510$ & -194 \\
2,372 & 1,255 & $-0,213$ \\
& $-1,766$ & 0,095 \\
& & $-0,308$ \\
$-2,686$ & 1,760 & \\
2,021 & $-2,447$ & 0,021 \\
$-4,707$ & 4,207 & 0,390 \\
& & $-0,369$ \\
7,333 & $-6,312$ & $-0,885$ \\
4,243 & $-3,867$ & $-0,145$ \\
3,090 & $-2,445$ & $-0,740$ \\
& & \\
$-4,830$ & 4,342 & $-0,048$ \\
$-0,468$ & 0,242 & $-0,001$ \\
$-4,362$ & 4,100 & $-0,047$ \\
& & \\
1,553 & $-1,065$ & $-0,148$ \\
3,609 & $-3,397$ & $-0,055$ \\
$-2,056$ & 2,332 & $-0,093$ \\
\hline
\end{tabular}

Fonte: Elaboração própria, a partir dos dados da pesquisa.

Com base nesses resultados, verificou-se que a variação da produtividade do trabalho ao longo do período se explica mais pela produtividade da terra do que pela relação terra-homem. No entanto, a relação terra-homem teve mais efeitos sobre a produtividade do trabalho em determinados períodos, afetando de alguma forma o emprego rural. Em 1980-1985, somente as Mesorregiões Jaguaribe e Sul Cearense foram menos explicadas pela produtividade da terra do que pela relação terrahomem. Também em 1985-1995, predominou a relação terra-homem como componente mais explicativo da produtividade do trabalho nas Mesorregiões Norte Cearense e Sertões Cearenses. A saída dos trabalhadores do campo estaria assim relacionada à mecanização do trabalho.

RER, Rio de Janeiro, vol. 44, no 03, p. 503-524, jul/set 2006 - Impressa em setembro 2006 
Há muitas discussões acerca dos motivos que estariam então levando à migração rural-urbana. Em diversas regiões do mundo e no sul do país, cogita-se em que o maior uso da mecanização no campo é responsável pela saída dessa mão-de-obra. Entretanto, os resultados empíricos já desmistificaram esses rumores, pelo menos no âmbito nacional.

Acredita-se que neste estado tão devastado pela crise de produção gerada pelas secas, a razão de tal migração esteja mais nas condições precárias de vida do homem no campo do que na mecanização, especialmente nas regiões mais afetadas pela estiagem prolongada.

\subsubsection{Produtividade do Capital}

A produtividade do capital, que consiste na relação entre o índice agregado do produto e o índice do fator capital, acompanha a tendência da produtividade do trabalho. A exemplo das análises precedentes, quase não houve variações de produtividade no período em estudo. Contudo, ressalte-se que os Sertões Cearenses e Centro-Sul Cearense apresentaram as menores produtividades, enquanto o Jaguaribe revelou as maiores, ainda que decrescentes ao longo do período. Nos Sertões Cearenses, têm-se os solos menos produtivos e maiores são as irregularidades das chuvas, características também comuns ao Centro-Sul Cearense. Já o Jaguaribe, apesar de apresentar as melhores condições de produção, apresenta redução das áreas exploradas em todo o período analisado. Também os menores índices ocorreram em 1980, com exceção das Mesorregiões Metropolitana de Fortaleza e Jaguaribe, como se pode observar na Tabela 4, que possivelmente foram menos afetadas pelas estiagens ocorridas nesse período ou pelas condições naturais de cada uma ou por maiores incentivos governamentais.

Acredita-se que as variações pouco expressivas na produtividade do capital no período analisado devem ser explicadas em razão do pouco uso dos insumos modernos, em favor de fatores como de terra e trabalho. Dessa forma, os investimentos na agropecuária não estariam sendo suficientes para a melhoria na infra-estrutura de transportes, para a adoção de novas tecnologias e profissionalização do homem do campo.

O Jaguaribe, por sua vez, destaca-se pelos fatores já mencionados, maior assistência técnica e uso das práticas de irrigação, daí o melhor 
desempenho no referido ano, além de possuir a maior população ativa do estado. Esses fatores podem explicar o elevado ganho de produtividade no ano de 1980. A partir desse ano, a população dessa Mesorregião bem como a quantidade de terras exploradas foi diminuindo ao longo do período analisado.

Em síntese, verifica-se que, ao longo do período de 1975-1995, as produtividades da terra, trabalho e capital revelaram pequenas mudanças de comportamento. Os resultados observados nesse período não apresentaram variações muito acentuadas, além de não demonstrarem tendência clara, já que os sinais variaram constantemente em períodos seguidos.

Tabela 4 - Índice de Produtividade do Capital para o Estado do Ceará e Mesorregiões, 1975-1995

\begin{tabular}{l|l|r|r|r||r}
\hline \hline & MESORREGIÕES & $\mathbf{1 9 7 5}$ & $\mathbf{1 9 8 0}$ & \multicolumn{1}{c|}{$\mathbf{1 9 8 5}$} & \multicolumn{1}{c}{$\mathbf{1 9 9 5}$} \\
\hline \hline & CEARÁ & $\mathbf{1 0 0 , 0 0}$ & $\mathbf{9 8 , 8 0}$ & $\mathbf{9 9 , 9 5}$ & $\mathbf{1 0 0 , 0 0}$ \\
1 & Noroeste Cearense & 100,00 & $\mathbf{7 9 , 9 8}$ & 103,72 & 100,00 \\
2 & Norte Cearense & 100,00 & 92,04 & 95,29 & 101,06 \\
3 & Metropolitana de Fortaleza & 100,00 & 101,72 & 102,65 & 100,05 \\
4 & Sertões Cearenses & 100,00 & 88,48 & 94,28 & 94,50 \\
5 & Jaguaribe & 100,00 & 144,98 & 104,04 & 95,13 \\
6 & Centro-Sul Cearense & 100,00 & 86,28 & 96,34 & 96,26 \\
7 & Sul Cearense & 100,00 & 100,68 & 100,94 & 100,27 \\
\hline \hline
\end{tabular}

FONTE: Elaboração própria, a partir dos dados da pesquisa.

\subsection{Produtividade Total dos Fatores}

A produtividade total dos fatores, devidamente ponderada pelas participações do conjunto de produtos e fatores, expressa as alterações ocorridas em ambos. Assim, como mencionado, quando o índice de produto supera o de fatores, tem-se uma situação com ganhos de produtividade. Analogamente, com a situação inversa, tem-se perdas de produtividade. Verificou-se a mesma tendência das produtividades parciais, qual seja, comportamento oscilatório com pequenas alterações de produtividade, como pode ser observado na Tabela 5 . 
Tabela 5 - Produtividade Total dos Fatores para o Estado do Ceará e Mesorregiões, 1975-1995

\begin{tabular}{|c|c|c|c|c|c|}
\hline & MESORREGIÕES & 1975 & 1980 & 1985 & 1995 \\
\hline & CEARÁ & 100,00 & 84,74 & 101,42 & 99,34 \\
\hline 1 & Noroeste Cearense & 100,00 & 67,33 & 105,51 & 97,97 \\
\hline 2 & Norte Cearense & 100,00 & 76,55 & 98,26 & 99,08 \\
\hline 3 & $\begin{array}{l}\text { Metropolitana de } \\
\text { Fortaleza }\end{array}$ & 100,00 & 108,06 & 102,43 & 99,86 \\
\hline 4 & Sertões Cearenses & 100,00 & 76,78 & 96,60 & 92,71 \\
\hline 5 & Jaguaribe & 100,00 & 116,60 & 103,28 & 95,38 \\
\hline 6 & Centro-Sul Cearense & 100,00 & 71,12 & 100,46 & 99,41 \\
\hline 7 & Sul Cearense & 100,00 & 93,60 & 100,10 & 100,72 \\
\hline
\end{tabular}

Fonte: Elaboração própria, a partir dos dados da

pesquisa.

Em geral, os Sertões Cearenses apresentaram as menores produtividades, tanto parciais como total. Isso pode ser explicado pelas condições de produção inerentes à Mesorregião, menos favoráveis relativamente às demais, como maior escassez de chuvas, solos menos férteis, pecuária extensiva, embora essa Mesorregião não tenha apresentado tendência decrescente como outras mesorregiões.

De forma similar, o ano de 1980 revelou os menores índices da produtividade total dos fatores, excetuando-se as mesorregiões Metropolitana de Fortaleza e Jaguaribe, que expressam seus maiores índices nesse período, pelos fatores já referidos. Também o ano de 1995 destacou-se por baixas produtividades. Contudo, o Sul Cearense apresentou melhores resultados, pelo fato de possuir os melhores solos do Estado, como é de conhecimento geral, podendo também ser comprovado pelo menor uso de adubos em relação às demais mesorregiões.

Os ganhos de produtividade total no Noroeste Cearense em 1985 também podem ser explicados por maior uso de adubos e energia, maior número de estabelecimentos rurais e maior regularidade climática. Esses fatores compensam o fato de a população rural em idade ativa nesta Mesorregião ser a menor do estado. Já o Centro-Sul Cearense, segundo maior usuário de assistência técnica, conservação do solo e práticas de 
irrigação, ainda que possua a menor extensão em hectares produtivos, também revelou ganhos de produtividade em 1985.

Acredita-se que as perdas de produtividade em 1995 decorreram da descontinuidade do programa de crédito rural, intensificado após 1985; à maior descentralização do Governo, com menores intervenções na agricultura; além das condições macroeconômicas específicas do Plano Real, em 1994, o que resultou em mudanças na política cambial, interferindo nos preços de insumos e produtos.

Percebe-se que, se de um lado, o fenômeno climático das secas pode ajudar a explicar as variações na produtividade, de outro este não deve ser o único fator responsável por tais variações. Ademais, deve-se levar em conta o fato de que, mesmo nas regiões em que tradicionalmente há maior regularidade climática, como nas mesorregiões mencionadas, ocorre em determinados anos e lugares específicos a incidência de secas parciais ou secas verdes.

No semi-árido cearense, a incorporação de tecnologias de irrigação pode transformar o uso da terra. Contudo, essas tecnologias não se adequam a todas as mesorregiões, além de serem dispendiosas para os pequenos agricultores, em razão de seu baixo poder aquisitivo. Surge, então, a necessidade de intervenção governamental, através das políticas compensatórias.

O setor agropecuário cearense é fortemente dependente das chuvas para o sucesso da produção agropecuária, em grande parte voltada para a subsistência. Isso aumenta a necessidade de buscar meios alternativos de renda não agropecuária para o sustento familiar. As necessidades de manter subsistência reduzem o potencial da produção destinada às exportações e com isso impossibilita a geração das divisas.

Além da importância dos fatores aludidos, há uma concordância de opiniões de que o excedente agropecuário produzido internamente e de forma crescente é uma condição necessária para um desenvolvimento bem-sucedido em lugares com baixa produtividade agropecuária e população em crescimento.

Chama-se a atenção para algumas divergências, embora pequenas, entre os resultados de produtividade alcançados neste trabalho e os outros estudos que enfocaram a agropecuária cearense. Acredita-se que estas são conseqüências dos seguintes fatores: 
a) como o presente estudo foi desagregado por mesorregiões, houve uma diferença nos valores impressos nas publicações do IBGE, haja vista que os valores individuais não correspondem ao valor total do estado nessas publicações;

b) o conjunto do valor da produção dos produtos selecionados foi diferente, uma vez que neste trabalho foram utilizados somente os 24 principais produtos da agropecuária cearense, considerando que os demais tinham participações insignificantes;

c) as análises anteriores foram realizadas com valores da produção, enquanto esta com quantidades produzidas, em virtude dos fatores já aludidos.

\section{Conclusão}

Os resultados permitem concluir que ocorreram pequenas variações cíclicas na produtividade da terra, do trabalho e do capital, para o Estado do Ceará e mesorregiões, no período analisado. Da mesma forma, a produtividade total dos fatores também apresentou pequenas alterações cíclicas para o estado e mesorregiões no período em análise, confirmando a análise parcial. Portanto, as mudanças ocorridas foram tímidas.

Não houve mudanças significativas de tecnologias, com utilização de insumos modernos ou melhoria na capacitação da mão-de-obra ou, ainda, as políticas direcionadas à agropecuária cearense não foram eficazes, dada a pouca variação de produtividade. Se essa situação perdurar, podem ocorrer sérios problemas para o estado, em particular para as mesorregiões com menores produtividades, tais como descapitalização dos produtores rurais, deficiência na infra-estrutura de produção, migração dos produtores e perda de competitividade.

O ano de 1980, em geral, revelou as menores produtividades. Acredita-se que este fato seja, em parte, conseqüência das secas ocorridas nesse período. Isso se reforça pelo fato da Mesorregião do Jaguaribe ter apresentado comportamento diferenciado das demais mesorregiões, o que se atribui às melhores condições de produção, proporcionadas principalmente pela irrigação e pela exploração pecuária.

Dessa forma, para possibilitar o desenvolvimento das mesorregiões, faz-se mister haver maciços investimentos na agropecuária, mais 
treinamentos voltados para a atividade, mais incentivos à utilização de tecnologias apropriadas ao tipo de atividade de cada mesorregião, criação de associações ou cooperativas para fortalecer a produção e comercialização de insumos e produtos, além de maior conhecimento do mercado e das cadeias produtivas.

Como medida para promover o desenvolvimento agrícola, o governo do Estado tem incentivado o cultivo em terras com potencialidades de irrigação (caso do Jaguaribe). Contudo, também são necessárias políticas específicas voltadas para aquelas mesorregiões que não receberam os mesmos incentivos e que, por estarem situadas em áreas cujas condições edafo-climáticas são menos favoráveis, este fato torna a vida do trabalhador rural mais difícil, podendo levar à migração rural-urbana.

\section{Referências bibliográficas}

CARTAXO, S. M. S. Contribuição da produtividade total para o crescimento do produto no Brasil no período de 1977-1985. 1989. (Dissertação de Mestrado em Economia) - UFC/CAEN, Fortaleza, 1989.

CUNHA, M. S. da. Distribuição espacial e competitividade na agropecuária brasileira. In:XXXIX CONGRESSO BRASILEIRO DE ECONOMIA E SOCIOLOGIA RURAL, Recife-PE, 2001. ANAIS... Recife: 2001. CD-ROM.

DIAS, G. L. da S., AMARAL, C. M. Mudanças estruturais na agricultura brasileira: 1980-1998. Série desarrollo productivo. Red de Desarrollo Productivo y Empresarial, CEPAL. Santiado de Chile, enero de 2001.

GASQUES, J. G., CONCEIÇÃO, J. C. P.R. da (org.) et al. Transformações da agricultura e políticas públicas. Brasília: Instituto de Pesquisas Econômicas Aplicada (IPEA), capítulo 1, 2001.

GASQUES, J. G., CONCEIÇÃO, J. C. P.R. da. Transformações estruturais da agricultura e produtividade total dos fatores. Brasília: IPEA (Instituto de Pesquisa Econômica Aplicada), novembro/2000 (a). (Texto para discussão n. 768).

Produtividade Total dos Fatores na Agricultura. Preços agrícolas. São Paulo, n.165, p.3-7, julho/2000 (b). 
. Crescimento e produtividade da agricultura brasileira. Brasília: IPEA (Instituto de Pesquisa Econômica Aplicada), julho/1997. (Texto para discussão n. 502).

HOFFMANN, R. Estatística para economistas. São Paulo: Pioneira, 1980.

KHAN, A. S., MOURA, A. C. F., SILVA, L. M. R., et alii. Assitência técnica, produtividade diferencial e benefícios sociais no Estado do Ceará. In: XXXVII CONGRESSO BRASILEIRO DE ECONOMIA E SOCIOLOGIA RURAL, Foz do Iguaçu-PR, 1999. ANAIS... Foz do Iguaçu: 1999. p. 1-10.

LEMOS, J. de J. S., FERNANDES, A. J., BRANDT, S. A. Produtividade de fatores, retornos de escala e desenvolvimento agrícola. Revista de Economia e Sociologia Rural, março/1984.

REIS JÚNIOR, H. da S. A Modernização agrícola e a questão agrária no Ceará: o caso da Microrregião da Ibiapaba. 1996. (Dissertação de Mestrado em Economia Rural) - UFC/CCA/DEA, Fortaleza, 1996.

ROSA, A. L. T. da, ALVES, F. F. Desempenho Recente da Economia Cearense. Efeitos da globalização sobre a economia cearense. Fortaleza: IPLANCE (Instituto de Pesquisa e Informações Econômicas do Ceará), 2001.

STADUTO, J. A. R., FREITAS, C. A. de. Uma avaliação da mudança estrutural da produção agrícola brasileira no período de 1960-1995. In: XXXIX CONGRESSO BRASILEIRO DE ECONOMIA E SOCIOLOGIA RURAL, Recife-PE, 2001. ANAIS... Recife: 2001. CD-ROM.

VICENTE, J. R., ANEFALOS, L. C., CASER, D. V. Produtividade agrícola no Brasil, 1970-1995. Agricultura em São Paulo. São Paulo: v.48, n.2, p.33-55, 2001.

Produtividade de fatores na agricultura brasileira, 1970-1995: influência de capital humano, insumos modernos e recursos naturais. (mimeo)

Recebido em janeiro de 2006 e revisto em maio de 2006 